\title{
Manifestaciones extranodales del linfoma. Diseminación renal y apendicular
}

\section{Extranodal Lymphoma. Renal and Appendiceal Main Radiological Findings}

\author{
Leticia Moreno Caballero ${ }^{1}$ Raquel Navas Campo ${ }^{1}$ \\ David Ibáñez Muñoz ${ }^{1}$ \\ ${ }^{1}$ Servicio de Radiodiagnóstico Hospital Clínico Universitario Lozano \\ Blesa, Av. San Juan Bosco 15, Zaragoza, España
}

Rev Argent Radiol 2020;84:30-32.
Diego Solís Gutiérrez ${ }^{1}$ Enrique Álvarez Arranz ${ }^{1}$

Address for correspondence Leticia Moreno Caballero, Calle Ramiro I de Aragon $\mathrm{n}^{\circ} 383^{\circ} \mathrm{B}, \mathrm{CP} 50017$, Zaragoza, España (e-mail: leticiamc92@gmail.com).

completó el estudio con serologías de sífilis, virus de la inmunodeficiencia humana (VIH), hepatitis y citomegalovirus; biopsia de las lesiones de cuero cabelludo, cuyo resultado reveló linfoma / leucemia linfoblástica T; y se practicó punción aspirativa con aguja fina (PAAF) de adenopatía cervical, que confirmó el cuadro linfoide monomorfo. También se solicitó TC toracoabdominopélvica con contraste intravenoso (CIV) que puso de manifiesto: una masa mediastínica anterior que englobaba vasos con leve compresión y desplazamiento sugestiva de conglomerado adenopático y múltiples lesiones focales renales, bilaterales, así como engrosamiento apendicular sugestivos de infiltración linfomatosa (-Figs. 1-3).

La extensión extranodal del linfoma afecta con frecuencia el sistema genitourinario, sobre todo los riñones. Generalmente ocurre en el contexto de un linfoma no Hodgkin diseminado. En más de la mitad de los casos, la diseminación renal o perirrenal se detecta en la presentación inicial. Normalmente es clínicamente asintomático. ${ }^{1}$

La modalidad de elección para su diagnóstico es la TC con CIV. La imagen en fase nefrográfica a los 80 segundos es la más sensible para la detección de lesiones corticales renales. ${ }^{1,2} \mathrm{La}$ resonancia magnética (RM), es útil en pacientes con contraindicación de administración intravenosa de contraste yodado. La ecografía es la menos sensible de las tres. ${ }^{1}$

Existe una amplia variedad de manifestaciones radiológicas. ${ }^{1,3}$ La presencia de múltiples lesiones corticales nodulares es la forma más común, como en nuestro caso. Suelen ser bilaterales, de tamaño variable, típicamente de 1 a $4,5 \mathrm{~cm}$ de diámetro. Ante dicho hallazgo y los múltiples diagnósticos received

June 6, 2018

accepted

May 8, 2019
DOI https://doi.org/

$10.1055 / \mathrm{s}-0039-1692462$. ISSN 1852-9992.
Copyright ( $)$ 2020, Sociedad Argentina de Radiología. Publicado por Thieme Revinter Publicações Ltda., Rio de Janeiro, Brazil. Todos los derechos reservados.
License terms

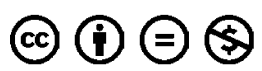




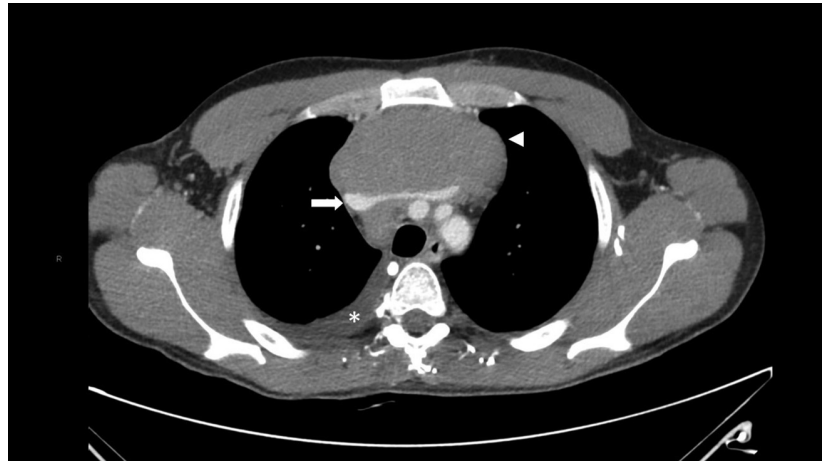

Fig. 1 Imagen de TC en plano axial y adquisición en fase portal. Voluminosa masa de densidad similar al músculo, homogénea, bien delimitada, en mediastino anterior de unos $100 \times 50 \mathrm{~mm}$ de diámetro máximo (cabeza de flecha) que engloba estructuras vasculares y las desplaza (flecha), compatible con conglomerado adenopático. Derrame pleural derecho (asterisco).

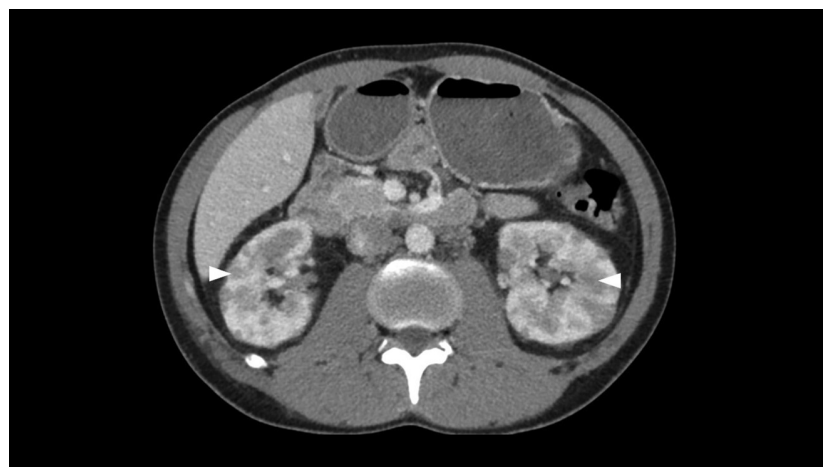

Fig. 2a Imagen de TC en plano axial y adquisición en fase portal. Riñones de tamaño y morfología normales con múltiples lesiones focales, hipodensas, bilaterales y de aspecto sólido (cabeza de flecha), compatible en el contexto del paciente con infiltración linfomatosa.

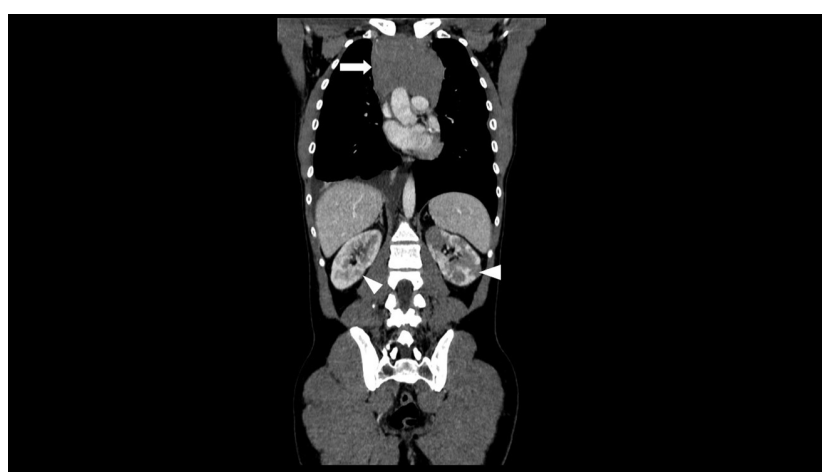

Fig. 2b TC con reconstrucción multiplanar (MPR) coronal oblicua y adquisición en fase portal. Se identifica la masa mediastínica descrita en - Figura 1 (flecha) y las múltiples lesiones focales hipodensas, en región cortical de ambos riñones (cabeza de flecha).

diferenciales que plantea (metástasis, carcinoma de células renales, pielonefritis, carcinoma de células transicionales, etc.) conviene completar el estudio con biopsia, si es el único hallazgo linfomatoso., ${ }^{2,3}$ En la TC sin CIV, aparecen como lesiones con una atenuación ligeramente más alta que la del parénquima circundante. La TC con CIV en fase nefrográfica es esencial porque muchas lesiones son pequeñas y afectan a la

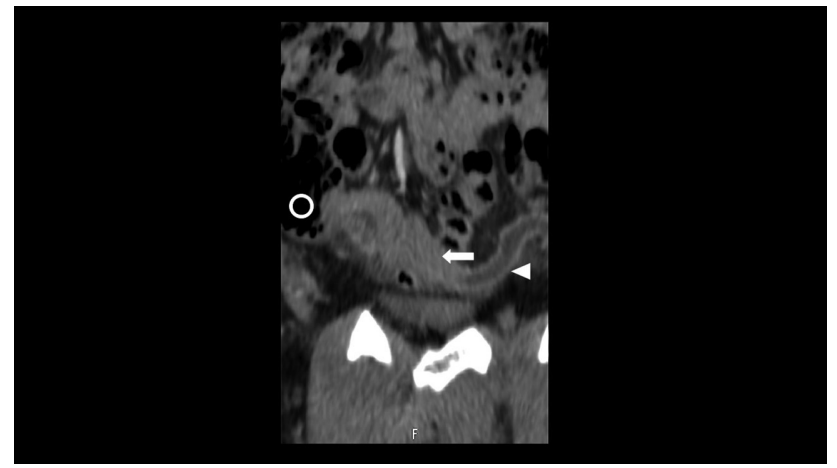

Fig. 3a Imagen de TC con reconstrucción curva siguiendo el eje apendicular. Se identifica apéndice dependiente de ciego (círculo) con su tercio proximal y medio engrosado de contenido sólido y realce homogéneo en relación con afectación linfomatosa (flecha), y cambios inflamatorios en su tercio distal (cabeza de flecha).

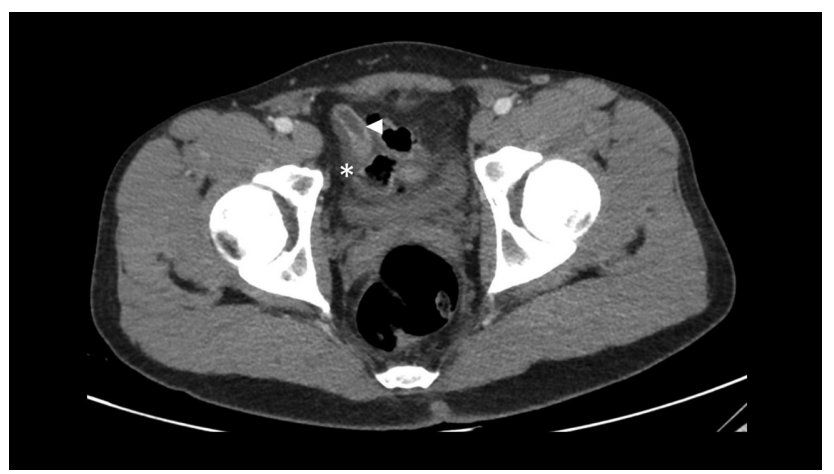

Fig. 3b. Imagen de TC en plano axial y adquisición en fase portal. Detalle del extremo distal del apéndice con cambios inflamatorios, con aumento del calibre y realce parietal, con diámetro transverso máximo de $8 \mathrm{~mm}$ (cabeza de flecha) y con líquido libre periapendicular (asterisco), secundario a la obstrucción por afectación linfomatosa proximal.

porción medular de los riñones, con mínima deformidad cortical. Los depósitos linfomatosos realzan menos que el tejido renal normal y aparecen como masas relativamente homogéneas e hipodensas. ${ }^{1,2}$

Por otro lado, existe la extensión retroperitoneal contigua, que es el segundo patrón más común. Se observan grandes masas retroperitoneales que invaden o desplazan el riñón adyacente. ${ }^{1,3}$ Generalmente, las arterias y venas renales permanecen permeables. Sin embargo, la extensión al sistema colector renal puede causar obstrucción e hidronefrosis. ${ }^{2}$

Otras formas menos frecuentes de presentación son la lesión solitaria, típicamente hipovascular y con un realce mínimo después de la administración de CIV y la enfermedad perirrenal que, aunque normalmente se manifiesta como un aumento de tejido blando perirrenal homogéneo que comprime el parénquima normal, en algunas ocasiones puede presentar otras formas, como la infiltración del seno renal, el engrosamiento de la fascia de Gerota y las masas perirrenales. $^{1,2}$ Tampoco es frecuente que el linfoma se manifieste como enfermedad infiltrativa en forma de nefromegalia difusa con preservación del contorno renal (la TC con CIV puede demostrar realce heterogéneo de los 
riñones, pérdida de la diferenciación normal corticomedular e infiltración grasa del seno renal), o como masa renal sinusal, reemplazando el seno renal normal por una masa homogénea. $^{1-3}$

En cuanto al linfoma apendicular, es poco frecuente y difícil de sospechar en ausencia de otros hallazgos linfomatosos. ${ }^{4} \mathrm{La}$ etiología más frecuente es por extensión de un linfoma cecal hacia la base apendicular. ${ }^{5}$ Las manifestaciones clínicas típicas son similares a las de la apendicitis aguda y la TC también es de elección. ${ }^{5}$ El apéndice puede agrandarse masivamente, pero generalmente mantiene su apariencia. ${ }^{5}$ El engrosamiento mural difuso tiene atenuación de tejido blando en la TC. ${ }^{4}$ La tomografía por emisión de positrones (PET) con fluordesoxiglucosa puede demostrar una captación anormal e intensa del radiotrazador en la región del apéndice. ${ }^{6}$

Confidencialidad de los datos

Los autores declaran que han seguido los protocolos de su centro de trabajo sobre la publicación de datos de pacientes, y que todos los pacientes incluidos en el estudio han recibido información suficiente y han dado su consentimiento informado por escrito para participar en dicho estudio.

\section{Responsabilidades Éticas}

Derecho a la privacidad y consentimiento informado. Los autores declaran que en este artículo no aparecen datos de pacientes y se cuenta con el consentimiento informado del paciente recogido en su historia clínica.

Protección de personas y animales. Los autores declaran que para esta investigación no se han realizado experimentos en seres humanos ni en animales.

Conflicto de Intereses

Los autores del trabajo declaran no tener ningún conflicto de intereses.

\section{Bibliografia}

1 Sheth S, Ali S, Fishman E. Imaging of renal lymphoma: patterns of disease with pathologic correlation. Radiographics. 2006;26(04): $1151-1168$

2 Urban BA, Fishman EK. Renal lymphoma: CT patterns with emphasis on helical CT. Radiographics. 2000;20(01):197-212

3 Larrañaga N, de Salazar A, Oyarzún A, Espil G, Kozima S. Patrones imagenológicos por TCMD del linfoma renal. Rev Argent Radiol. 2015;79(03):134-138

4 Pickhardt PJ, Levy AD, Rohrmann CA Jr, Kende AI. Primary neoplasms of the appendix: radiologic spectrum of disease with pathologic correlation. Radiographics. 2003;23(03):645-662

5 Ghai S, Pattison J, Ghai S, O'Malley ME, Khalili K, Stephens M. Primary gastrointestinal lymphoma: spectrum of imaging findings with pathologic correlation. Radiographics. 2007;27 (05):1371-1388

6 Paes FM, Kalkanis DG, Sideras PA, Serafini AN. FDG PET/CT of extranodal involvement in non-Hodgkin lymphoma and Hodgkin disease. Radiographics. 2010;30(01):269-291 